\title{
ULTRAESTRUCTURA DE LOS ACINOS SUDORÍPAROS DE LAS GLÁNDULAS PELVIANAS DE CHAETOPHRACTUS VILLOSUS (MAMMALIA, DASYPODIDAE)
}

\author{
Silvia Estecondo ${ }^{1}$ \\ Elena J. Galíndez ${ }^{1}$ \\ Emma B. Casanave ${ }^{1,2}$
}

\begin{abstract}
ULTRASTRUCTURE OF SUDORIPAROUS ACINI OF PELVIAN GLANDS OF CHAETOPHRACTUS VILLOSUS (MAMMALIA, DASYPODIDAE). The acini of pelvian glands of Chaetophractus villosus (Desmarest, 1804) consisted of an inner layer of secretory cells and an outer layer of myoepithelial cells. Secretory cells have numerous secretory vacuoles. The secretion is released by exocytosis. Myoepithelial cells have numerous myofilaments that occupy much of the cytoplasm. There is a third cell type with an extremely electron-lucent cytoplasm.
\end{abstract}

KEYWORDS. Pelvian glands, sudoriparous acini, ultrastructure, Chaetophractus villosus.

\section{INTRODUCCIÓN}

Sobre la línea media del caparazón pelviano de algunos dasipódidos existen glándulas tegumentarias especializadas denominadas glándulas pelvianas. Las mismas están ubicadas en protuberancias que presenta el caparazón óseo en su cara interna (LAHILle, 1895; POCOCK, 1913; FernándEZ, 1922). En Chaetophractus villosus (Desmarest, 1804) y en Euphractus sexcinctus (L. 1758), dichas glándulas están constituidas por acinos sebáceos y acinos sudoríparos (FERnÁNDEZ, 1922; EsteCondo \& CASANAVE, 1998). En Chaetophractus vellerosus (Gray, 1865) solamente hay acinos sudoríparos (EsTECONDO et al., 1997). En este trabajo se estudia la ultraestructura de los acinos sudoríparos de las glándulas pelvianas de $C$. villosus.

\section{MATERIAL Y METODOS}

Ocho adultos de $C$. villosus, de ambos sexos, provenientes del área de Bahía Blanca, Provincia de Buenos Aires, Argentina, con pesos comprendidos entre 3,000 y 3,500 g, fueron anestesiados con Ketamina

\footnotetext{
1. Depto. de Biología, Bioquímica y Farmacia (DBByF), Universidad Nacional del Sur (UNS), San Juan 670, 8000, Bahía Blanca, Argentina (email:silviest@criba.edu.ar)

2. Investigador CONICET
} 
(3,5 mg/k, i.p). Con un torno manual, se seccionó el caparazón extrayendo las placas que contenían las glándulas pelvianas. El material se fijó por inmersión durante 6-12 horas, en el fijador de Karnovsky (KARNovsKY, 1965 ) diluido en buffer (GLAUERT, 1975) cacodilato de sodio 0,1 M, pH 7,4, a $4{ }^{\circ} \mathrm{C}$. Se decalcifićó por 12-20 días en EDTA 4,15\% (DeLDAR et al., 1985), a $4{ }^{\circ} \mathrm{C}$. Una vez decalcificado el material, se procedió a cortar piezas de $1 \mathrm{~mm}$ de espesor, se lavaron con buffer cacodilato y se postfijaron durante 2 horas en tetróxido de osmio $2 \%$ a $4{ }^{\circ} \mathrm{C}$, se deshidrataron en acetona de concentración creciente y se embebieron en resina Spurr. Se cortaron secciones ultrafinas con un ultramicrótomo LKB, usando cuchilla de diamante, se contrastó con citrato de plomo y acetato de uranilo y la observación se realizó con microscopio electrónico Jeol CXII.

El material está depositado en el laboratorio de Histología Animal de la Universidad Nacional del Sur, Bahía Blanca, Argentina.

\section{RESULTADOS}

Los acinos sudoríparos están formados por una sola capa de células secretoras y separando a éstas de la membrana basal, se ubican células mioepiteliales (m, fig. 1). Los núcleos de las células secretoras presentan un nucléolo (n) generalmente excéntrico (fig. 1). Estas células se caracterizan por la presencia de numerosas vacuolas ( $>$ ) de diferentes tamaños, muchas de ellas en proceso de fusión, que ocupan gran parte del citoplasma apical (figs. 1, 3). Las vacuolas están rodeadas por membrana, su contenido es filamentoso con algún cuerpo más denso (fig. 2) o con material de aspecto membranoso (fig. 3). El contenido se vierte a la luz por un proceso de exocitosis (fig. 2).

El retículo endoplasmático granular y el aparato de Golgi están muy desarrollados, las mitocondrias son muy numerosas y hay abundantes ribosomas libres. La superficie apical posee microvellosidades (*, figs. 1-4). Lateralmente, en la porción apical de la membrana plasmática, se distinguen complejos de unión entre células adyacentes, formados por uniones estrechas u oclusivas y desmosomas (d) (fig. 4). Entre las células secretoras y las mioepiteliales hay interdigitaciones (i) y desmosomas (fig. 5).

Los núcleos de las células mioepiteliales son ovales o elongados (fig. 6). El citoplasma es bastante homogéneo y oscuro, de apariencia fibrilar, debido a que está ocupado en su mayor parte por miofilamentos (flecha larga, fig. 6). Hay gran cantidad de vacuolas pinocíticas (v) alrededor de la membrana plasmática (fig. 7).

Basalmente se encuentran procesos celulares característicos, que se extienden dentro de la membrana basal (fig. 6). También hay hemidesmosomas (flecha corta) que aumentan la adherencia (figs. 1, 5,7). Las células mioepiteliales pueden estar unidas entre sí por desmosomas (fig. 7) o por interdigitaciones. Entre las células mioepiteliales y las secretoras se observan algunas células con citoplasma de menor densidad electrónica (c, fig. 8), poseen escasos organoides, en algunas se observan centríolos (cb, fig. 9).

En el tejido conectivo que ocupa el espacio interacinar, se encuentran vasos sanguíneos y fibras nerviosas amielínicas. En las fibras nerviosas se observan mitocondrias, neurotúbulos y dos tipos de vesículas: abundantes y pequeñas vesículas claras y algunas mayores con centro denso (fig. 10). También se encontraron terminaciones nerviosas amielínicas con ambos tipos de vesículas (t), entre las células mioepiteliales y las secretoras (fig. 11).

\section{DISCUSION}

Las células mioepiteliales son de origen epitelial y contráctiles. Poseen miofilamentos semejantes a los del músculo liso (ELLIS, 1965) y uno de los componentes de las miofibrillas es la actina (EMERMAN \& VogL, 1986; Moore et al., 1987). La función 

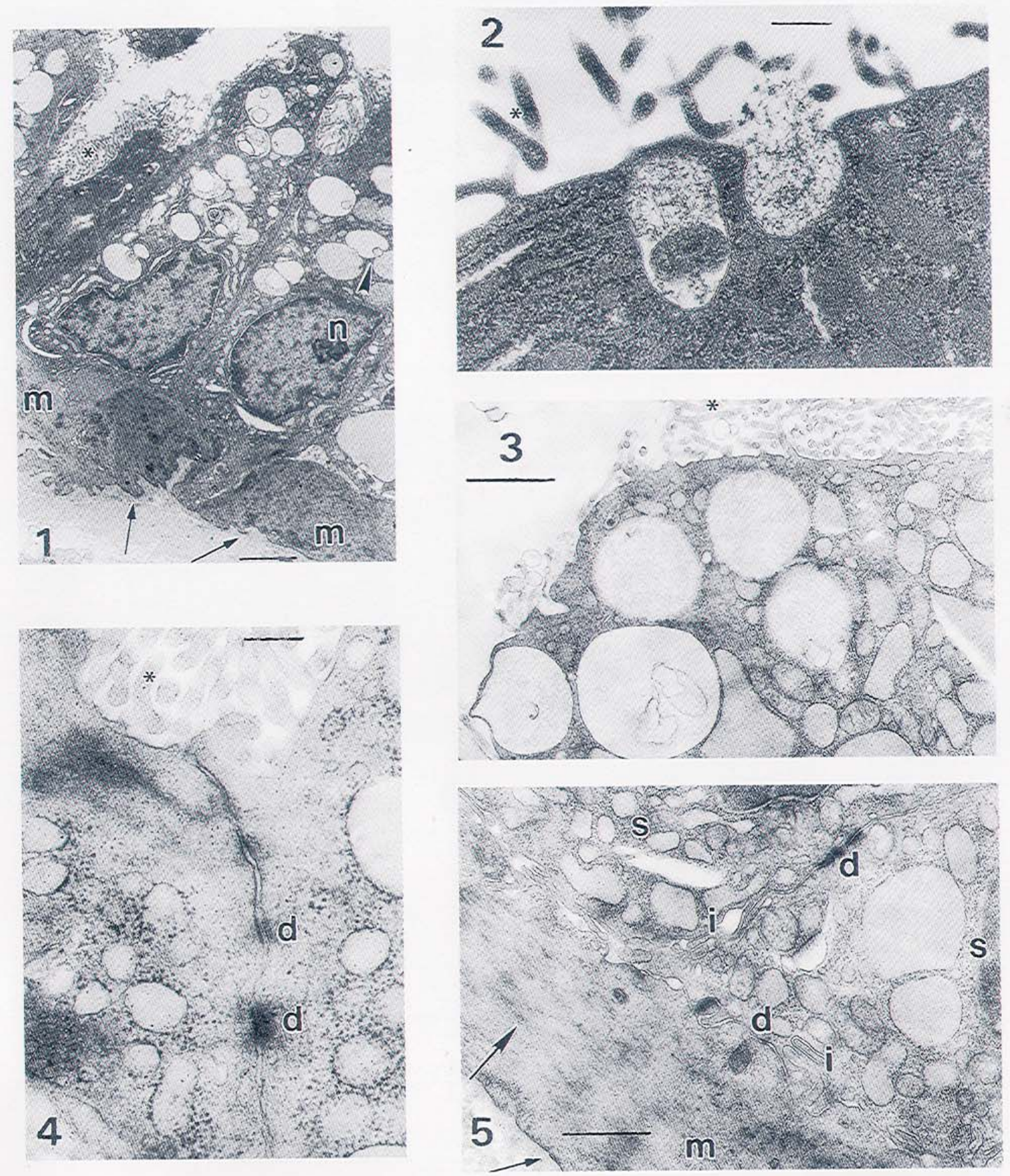

Figs. 1-5. Chaetophractus villosus: 1, porción de un acino sudoríparo; 2, vacuola secretora en proceso de exocitosis; 3 , citoplasma apical de una célula secretora; 4, unión lateral entre dos células secretoras; 5, unión entre dos células secretoras y una célula mioepitelial (d, desmosoma; i, interdigitaciones; m, célula mioepitelial; $\mathrm{n}$, nucléolo; s, célula secretora; cabeza de flecha, vacuola en proceso de fusión; flecha corta, hemidesmosomas; flecha larga, miofibrillas; ${ }^{*}$, microvellosidades). Barras: $0,25 \mu \mathrm{m}$, figs. 2,$4 ; 1 \mu \mathrm{m}$, figs. 3,$5 ; 2 \mu \mathrm{m}$, fig. 1. 


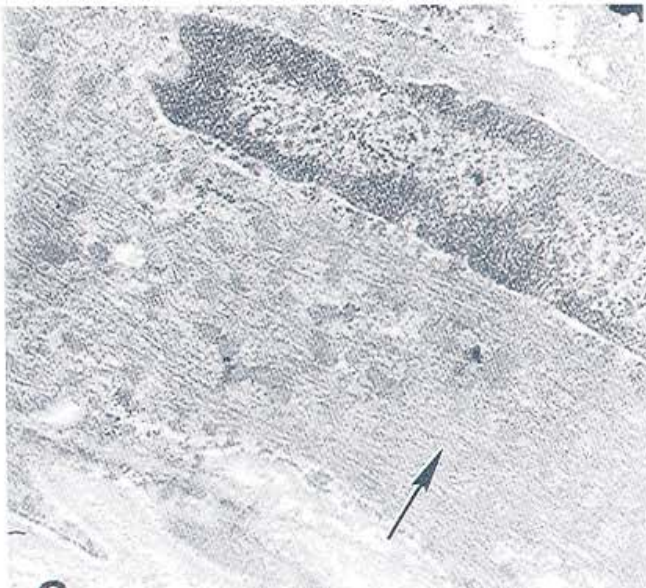

6
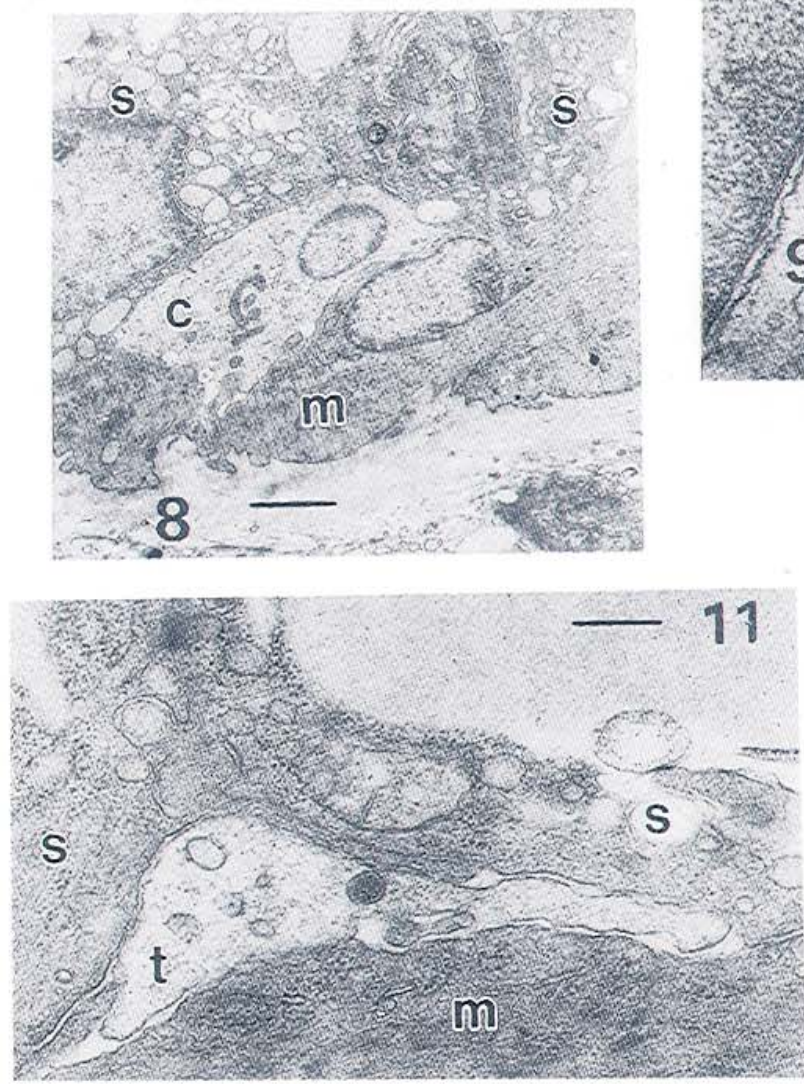
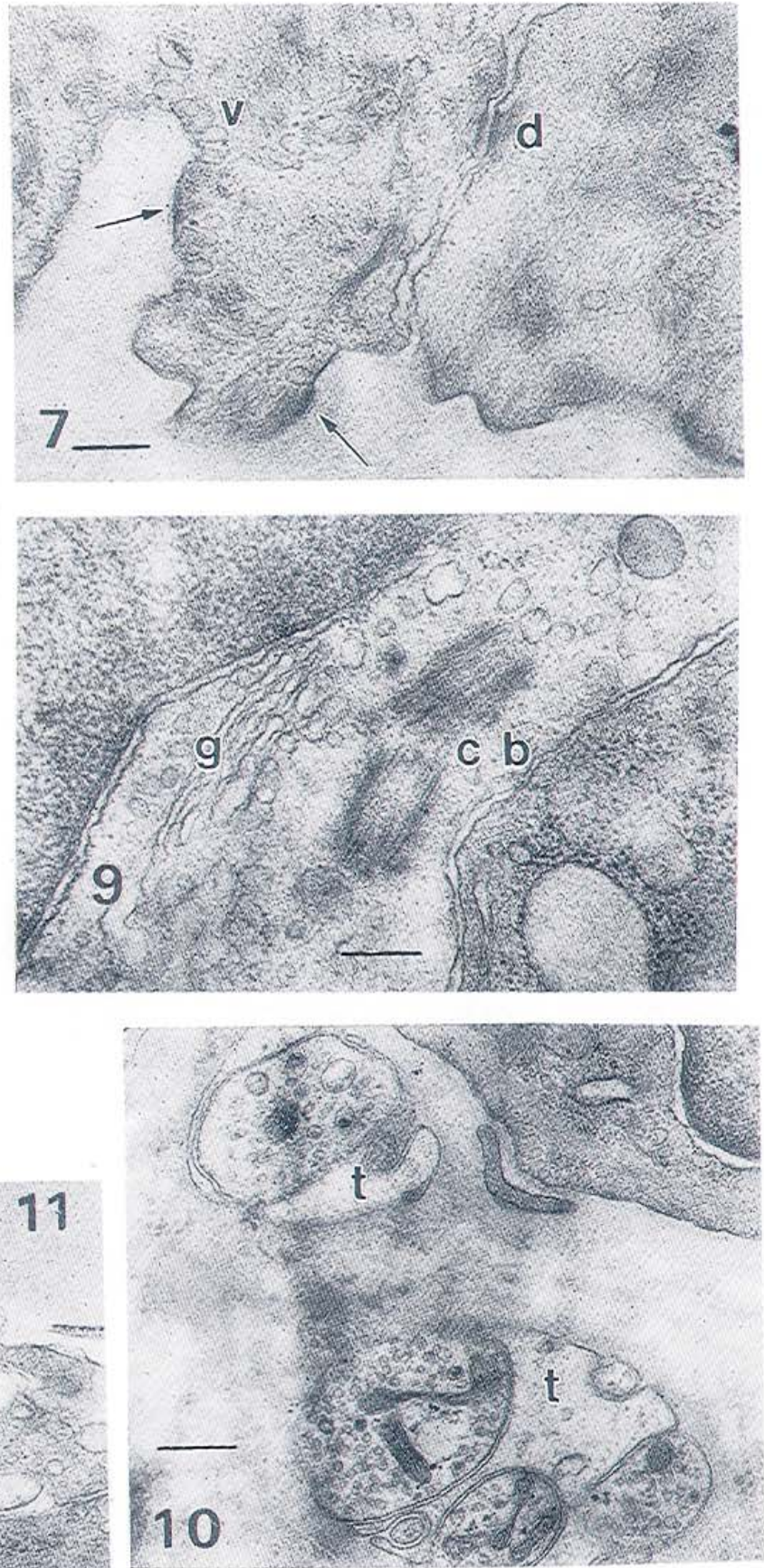

Figs. 6-11. Chaetophractus villosus: 6, célula mioepitelial; 7, porción basal de una célula mioepitelial con vacuolas pinocíticas; 8 , célula con citoplasma de baja densidad electrónica; 9 , citoplasma de una célula de baja densidad electrónica con centríolos; 10 , terminaciones nerviosas en el tejido conectivo interacinar; 11, terminación nerviosa entre dos células secretoras y una célula mioepitelial (c, célula con citoplasma de baja densidad electrónica; cb, centríolos; d, desmosomas; $\mathrm{g}$, aparato de Golgi; m, células mioepiteliales; p, procesos celulares; s, célula secretora; t, terminación nerviosa; v, vacuola pinocítica; flecha corta, hemidesmosomas; flecha larga, miofibrillas). Barras: 0,25 $\mu \mathrm{m}$, figs. 7, 9; 0,37 $\mu \mathrm{m}$, fig. 11; 0,50 $\mu \mathrm{m}$, figs. 6,$10 ; 2 \mu \mathrm{m}$, fig. 8 . 
de estas células incluye la contracción cuando la glándula es estimulada para secretar, comprimiendo las células parenquimáticas subyacentes, ayudando así a la expulsión de la secreción (REDMAN, 1994).

Las células mioepiteliales difieren en forma y distribución en las distintas glándulas y podría ser que estas diferencias se relacionen con propiedades físicas de la secreción (NAGATO et al., 1980). Según algunos autores, la variedad de configuraciones observada es difícil de asignar a la función general de expeler los productos de secreción hacia la luz. Entre las hipótesis emitidas, SATo et al. (1986), consideran que en vez de actuar simplemente como una bomba expelente, la función de las células mioepiteliales puede ser proveer soporte mecánico a la pared de los acinos secretores. Esto permitiría resistir el aumento de presión hidrostática luminal. SATOH et al. (1994) sugerieren que estas células parecen mantener el contorno de los acinos, sirviendo como exoesqueleto de los mismos. Para Redman (1994), también podrían ayudar en la propagación del estímulo secretorio u otro.

Aunque HrbBs (1958) sugiere que las células mioepiteliales de las glándulas sudoríparas humanas podrían desarrollarse en células secretoras y SATO et al. (1989), mencionan la posibilidad de intercambio entre los distintos tipos celulares de las mismas glándulas, no hemos observado células con características intermedias entre mioepiteliales y secretoras. Consideramos que ambos tipos celulares provienen de líneas celulares distintas. Al respecto, los resultados obtenidos coinciden con los de CUTLER \& CHAUDHRY (1973) en glándulas submandibulares de rata, REDMAN et al. (1980) en glándulas parótidas de rata, López et al. (1992a,b) en la glándula de Harder del hámster y MоRIмото et al. (1994) en glándulas sudoríparas humanas. A diferencia de lo descripto en otras glándulas, REDMAN et al. (1980) y NAGASHIMA \& ONO (1985), no encontramos células mioepiteliales con citoplasma claro.

Con respecto al tercer tipo celular identificado, células con citoplasma de baja densidad electrónica, corresponderían a las observadas en otras glándulas (REDMAN et al., 1980; LÓPEz et al., 1992a). La baja densidad electrónica se debería, principalmente, a la escasa presencia de organoides. Algunos autores (TANDLER, 1963) consideran que dichas células pueden ser precursoras involucradas en la renovación de células mioepiteliales. Sin embargo para otros (REDMAN et al., 1980), la relación de estas células con las células mioepiteliales dista de ser clara.

La presencia de vacuolas pinocíticas en las células mioepiteliales coincide con la reportada en glándulas salivares (TAKAHASHI, 1958; SCOTt \& PEASE, 1959) y sudoríparas (ELLIS, 1965). Las interdigitaciones entre las células mioepiteliales y las células secretoras, aquí observadas, aumentan el área de contacto entre dichas células, lo cual facilitaría el intercambio de metabolitos.

Las terminaciones nerviosas con vesículas, observadas en aposición con las células mioepiteliales, concuerdan con las reportadas en diversas glándulas, como las submucosas de la laringe humana (PASTOR et al.,1994) y las sublinguales de rata (TEMPLETON \& Thulin, 1978; NAGato \& TANDler, 1986). En relación con el contenido de las vacuolas, la heterogeneidad del mismo sugiere la presencia de sustancias de secreción de diferente naturaleza química.

\section{REFERENCIAS BIBLIOGRAFICAS}

Cutler, L.S. \& Chaudhry, A.P. 1973. Differentiation of the myoepithelial cells of the rat submandibular gland in vivo and in vitro: an ultrastructural study. J. Morphol., Philadelphia, 140 (3):343-354. 
Deldar, A.; LeWIS, H. \& Weiss, L. 1985. Bone lining cells and hematopoiesis: an electron microscopic study of canine bone marrow. Anat. Rec., New York, 213 (2):187-201.

EluIs, R.A. 1965. Fine structure of the myoepithelium of the eccrine sweat glands of man. J. Cell Biol., New York, 27:551-563.

Emerman, J.T. \& VoGL, W. 1986. Cell size and shape changes in the myoepithelium of the mammary gland during differentiation. Anat. Rec., New York, 216 (3):405-415.

Estecondo, S. \& CASAnAve, E.B. 1998. Morfología de las glándulas pelvianas de Euphractus sexcinctus (Linné, 1758) (Mammalia, Dasypodidae). Physis, Secc. C, Buenos Aires, 55 (128):33-37.

Estecondo, S.; CASANAve, E.B. \& Codón, S.M. 1997. Histología de las glándulas pelvianas de Chaetophractus vellerosus (Gray, 1865) (Mammalia, Dasypodidae). Iheringia, Sér. Zool., Porto Alegre, (83):85-90.

FERNANDEZ, M. 1922. Sobre la glándula pelviana y formaciones similares en desdentados recientes y fósiles. Revta Mus. La Plata, Ser. Zool., La Plata, 26:212-255.

GlaUerT, A. 1975. Fixation, dehydratation and embedding of biological specimens. Amsterdam, NorthHolland American Elsevier. 207p.

HisBs, R.G. 1958. The fine structure of human eccrine sweat glands. Am. J. Anat., Philadelphia, 103:201-217.

KARNOVSKY, M.J. 1965. A formaldehyde-glutaraldehyde fixative of high osmolarity for use in electron microscopy. J. Cell Biol., New York, 27:137-138.

Lahille, F. 1895. Contribution à l'étude des édentés à bandes mobiles de la République Argentine. An. Mus. La Plata, Sec. Zool., La Plata, 2:1-32.

López, J.M.; Tolivia, J. \& Álvarez Uria, M. 1992a. Posnatal development of the harderian gland in the syrian golden hamster Mesocricetus auratus. A light and electron microscopic study. Anat. Rec., New York, 233 (4):597-616.

. 1992b. An ultrastructural study of myoepithelium maturation during postnatal development of the hamster harderian gland. Anat. Embryol., Berlin, 186 (6):573-582.

Moore, D.M.; VogL, A.W. et al. 1987. Effect of calcium on oxytocin-induced contraction of mammary gland myoepithelium as visualized by NBD-phallacidin. J. Cell Sci., London, 88:563-569.

Morimoto, Y.; SAGA, K. \& TAKAHASHI, M. 1994. Proliferating cells in human eccrine and apocrine sweat glands. J. Invest. Dermatol., Baltimore, 102 (4):560-560.

NAGASHima, Y. \& ONo, K. 1985. Myoepithelial cell ultrastructure in the submandibular gland of man. Anat. Embryol., Berlin, 171 (3):259-265.

NAGATO, T. \& TANDLER, B. 1986. Gap-junctions in rat sublingual gland. Anat. Rec., New York, 214 (1):71-75.

NaGATO, T.; YoshidA, H. et al. 1980. A scanning electron microscope study of myoepithelial cells in exocrine glands. Cell Tissue Res., Berlin, 209:1-10.

PASTOR, L.M.; FERRAN, A. et al. 1994. Morphological and histochemical study of human submucosal laryngeal glands. Anat. Rec., New York, 239 (4):453-467.

Pососк, R.I. 1913. On dorsal glands in armadillos. Proc. zool. Soc., London, 73:1099-1103.

Redman, R.S. 1994. Myoepithelium of salivary glands. Micros. Res. Tech., New York, 27 (1):25-45.

Redman, R.S.; Sweney, L.R. \& Mclaughin, S.T. 1980. Differentiation of myoepithelial cells in the developing rat parotid gland. Am. J. Anat., Philadelphia, 158:299-320.

SAto, K.; KANG, W.H. et al. 1989. Biology of sweat glands and their disorders. 1. Normal sweat gland function. J. Am. Acad. Dermatol., Washington, 20 (4):537-563.

Sato, K.; Nishiyama, A. \& Kobayashi, M. 1986. Mechanical properties and functions of the myoepithelium in the eccrine sweat gland. Am. J. Physiol., Washington, 237 (5):177-184.

SAтоH, Y.; OомоRI, Y. et al. 1994. Configuration of myoepithelial cells in various exocrine glands of Guinea pigs. Anat. Embryol., Berlin, 189 (3):227-236.

SCOTT, B.L. \& PEASE, D.C. 1959. Electron microscopy of the salivary and lacrimal glands of the rat. Am. J. Anat., Philadelphia, 104:115.

TAKAHASHI, N. 1958. Electron microscopic studies on the ectodermal secretory glands in man. II. The fine structures of the mioepithelium in the human mammary and salivary glands. Bull. Tokyo Med. Dent. Univ., Tokyo, 5:177-192.

TANDLER, B. 1963. Ultrastructure of the human submaxillary gland. III. Myoepithelium. Z. Zellforsch., Berlin, 68:852-863.

Templeton, D. \& Thulin, A. 1978. Secretory, motor and vascular effects in the sublingual gland of the rat caused by autonomic nerve stimulation. Quart. J. Exp. Physiol., Edinburgh, 63:59-66.

Recebido em 24.06.1999; aceito em 26.10.1999. 